\title{
Encontro em Austin
}

BENEDITO NUNES

BENEDITO NUNES é professor da Universidade Federal do Pará e autor, entre outros livros, de $O$ Dorso do Tigre e Oswald Canibal (Editora Perspectiva) e Passagem para o Poético (Editora Ática).
No começo de 81 , professores visitantes num mesmo programa de literatura brasileira, na Universidade do Texas, em Austin, encontramo-nos, eu e Haroldo de Campos, sob o céu friorento de um indeciso inverno texano. Visitei-o num fim de tarde; primeiro locatário do apartamento, já familiarizado com as suas water bugs, foi indiferente a essas "baratas legionárias", "minúsculos abantesmas" a povoar o cotidiano de "Austinéia Desvairada", que li para o poeta, de um livro então em andamento, Passagem para $o$ Poético - (Filosofia e Poesia em Heidegger), um ou talvez dois capítulos referentes à concepção heideggeriana da linguagem e da poesia, em uma de cujas fontes principais, "Aus einem Gesprach von der Sprache" ("De uma conversação da linguagem"), já tinha ele se adentrado. Da nossa estirada conversa, por entre pausas da leitura, ficou-me na lembrança, por todos esses anos, a proposta de Haroldo para que travássemos os dois, algum dia, uma conversação intercorrente àquela, diálogo dentro de tal diálogo, concêntrico ou excêntrico à sua matéria.

Se o projeto não se realizou, a culpa foi toda de uma falsa expectativa minha. Aguardei que algo em prosa, no gênero ensaístico, viesse da parte do meu interlocutor. Hoje percebo que ele encetou a discussão sem demora, ali mesmo em Austin; mas o fez tomando a palavra em "Aisthesis, Kharis: Iki - Koan" - (glosa heideggeriana para Benedito Nunes), poema de "Austinéia Desvairada", inserto em $A$ Educação dos Cinco Sentidos (1985).

A reflexão a desenrolar-se nesta minha achega à obra de Haroldo de Campos - um escólio talvez impertinente, com a canhestra generalidade que soem ter as glosas filosóficas a textos poéticos - é uma tardia resposta do pretexto ao diálogo que motivou o citado poema-comentário:

"se heidegger tivesse olhado

para o ideograma

enquanto escutava o discípulo

japonês

(como pound olhou para ming ( ) sollua

com o olho cubista de gaudier-brzeska

depois de dar ouvido a fenollosa) 


\title{
teria visto que a cerejeira cereja koto ba (
}

)

\author{
das ding dingt
}

florchameja

no espaço indecidível

\author{
da palavra
}

$i k i "$

Nesse poema, exemplar em mais de um sentido, na obra de Haroldo de Campos, segundo mais adiante se verá, e que delineando a situação interlocutória do escrito heideggeriano, também sintetiza a complexa problemática da linguagem af retraçada, o pretexto a que me refiro, dentro da enunciação hipotética articulada dos seus treze versos, é a conseqüente falência do filossofo no entendimento de $i k i$, do significado dessa palavra que lhe escapou, por não ter olhado para o ideograma respectivo, enquanto escutava o discípulo discorrer acerca do significado dessa palavra. Se olhasse, teria visto que a cerejeira cereja - koto ba. E não olhou, porque o ouvir, o escutar, prevaleceu sobre o ver como atitude tomada relativamente ao dizer da linguagem. Toda a filosofia de Heidegger, na sua etapa final uma recusa à filosofia em nome de uma hermenêutica da linguagem, enquanto interpretação do ser como único objeto do pensamento, baseou-se efetivamente num escutar, numa auscultação da palavra escrita, dos textos fundamentais de poetas e filosofos.

A situação interlocutória de "Aus einem Gesprach von der Sprache - Zwischen einem Japaner und einem Fragenden" ("De uma Conversação da Linguagem - entre um Japonês e um Inquiridor”), recolhida em Unterwegs zur Sprache, remonta ao diálogo que Heidegger entreteve com o professor Tezuka, da Universidade Imperial de Tóquio, quando este o visitou na década de 50; era um dos últimos discípulos do filosofo alemão, o Conde Shuzo Kuki, já então falecido, e Tanabé, entre outros que o haviam freqüentado muito antes da publicação de Sein und Zeit (1927), quando ele ainda colaborava nos seminários de Edmund Husserl. Essa linhagem de alunos da terra do Sol Nascente justificava a visita; lembrada por Heidegger, a controvérsia amigável que outrora mantivera com o Conde Kuki sobre a aplicabilidade da estética européia à arte japonesa que este último postulava, motivou a conversação com Tezuka. Semelhante tentativa, na época de planetarização da técnica, exportando o modo de vida da sociedade industrial para todos os recantos do mundo, punha em risco, segundo o inquiridor, a identidade da maneira japonesa de ser, por efeito do mesmo espírito das línguas européias que impedira Heidegger de compreender, no momento daquela já remota controvérsia da década de 20, o sentido de iki, familiar ao velho mestre nipônico, que procurara aplicar à estética, depois de repensá-la fenomenologicamente, o estudo da arte de seu pars. Tal advertência orientará o confronto dos dois professores.

Toda a complexa, ambigua, e também tantas vezes equfvoca, problemática do filósofo de Freiburg, posterior à Analítica do Dasein, comprime-se nesse diálogo que, em ambos os interlocutores conduzido pelo empenho de contornarem, tão-só através do pensamento arrimado à linguagem, as estruturas conceptuais que os confinaram em mundos culturalmente estanques, repete, sob o resguardo das "destruições" encadeadas da metafísica e da estética, o passo para trás na direção do ser, origem esquecida e também princípio do novo começo do pensar - de um pensar essencialmente poético, tanto não-representacional, como não-proposicional, liberto da hegemônica dominância das categorias lógico-gramaticais. Já prenunciável em sua força remanente, mas inefetivo, e desse modo ainda por vir, esse pensar poético, dichtend Denken, difuso porém profuso, enraizado ora na polesis das línguas, ora no surto da palavra que nomeando funda o ser, possibilitaria, seja que o interpretemos no sentido de pensamento poético, ou no sentido de poesia do pensamento, ambos compatíveis com as oscilantes formulações do filóso- 
fo, o dizer essencial da linguagem, longe da expressão das vivências, a falar-nos sempre, principalmente nos textos dos pensadores poetas e naqueles dos poetas da poesia, de uma mesma correspondência entre o homem e o ser.

$\mathrm{Na}$ trilha dessa correspondência, poderiam os interlocutores compreender que o significado de $i k i$, algo assim como "graça", a kharis grega, para o japonês a verdade da arte, $\hat{e}$ independente da estética, e que a palavra com que na língua de Tezuka se nomeia a linguagem, koto ba - pétalas de flores surgidas do exultante esplendor da graça - $\varepsilon$, para o mestre alemão, a verdade da mesma linguagem, independentemente da lingǘstica, e incompatível com o idioma da metafísica que no sdeu "Sprache, glossa, língua e linguagem".

Anterior ao apofântico, na suge são de Marc Richir, essa verdade, raiz do poético, é o que a linguagem diz mostrando ou o que ela mostra dizendo. Estaria ar, em última análise, a poesia do pensamento pela hermenêutica buscada, e que só se mostra no dizer essencial a quem sabe ouvi-lo quando ausculta a palavra.

A primeira notação exemplar do poema de Haroldo de Campos é a reserva crítica à poesia do pensamento assim formulada, em que implica a hipótese da falência do filosofo no entendimento da palavra iki. Ora, também o nosso interlocutor tem incessantemente visado, quer na sua criação própria por meio do "verso solto, fecundante" ou do versiprosa galático, quer no transplante da criação em língua estrangeira por meio da tradução, o que também pode chamar-se de poesia do pensamento. Por que então a crítica? Uma breve recapitulação dos dois caminhos da prática meditante, exercida por Heidegger como hermeneuta da linguagem, poderá esclarecê-lo.

O primeiro caminho é a "escuta renovada" da palavra grega nos pré-socráticos para sondar-lhes o pensamento inaugural, ainda vizinho da origem que a filosofia como metafísica sufocou. O segundo, dirigido à interpretação de poetas preferenciais - de Hölderlin a Rilke, de Stefan George a Trakl-é também uma escuta de seus textos, como meio de deixar falar a linguagem. Um e outro, que pressupõem a instauração do ser pela linguagem, pressupõem igualmente, segundo a linha de pensamento desenvolvida sobretudo nos ensaios de Unterwegs zur Sprache, que acompanham o "Aus einem Gesprach von der Sprache", uma fundamentação em círculo: a linguagem instaura o ser, mas é o apelo desse mesmo ser que a funda e que nos põe a dialogar com ela. Por outro lado, não exclusivamente inter-humano, esse diálogo está na dependência do mesmo apelo, do qual o poeta é o Mensageiro. Destarte, o acesso dialogal que tem o filósofo à essência da linguagem, assim realizado como um falar escutado, sem outra mediação além da escuta ao ser que provoca o esforço mesmo de auscultação dos textos, dispensaria o caráter de signo da palavra.

Eis onde bate a restrição do autor de Signantia Quase Coelum, que tem realçado, como poeta e como ensaísta, a visibilidade, a corporeidade e a espacialidade da palavra poética enquanto signo. Heidegger não olhou para o ideograma, termo apenas mencionado, de raspão, na conversa dos dois professores. Se pudesse ter olhado com o olho de quem conhece - nesse caso, o de Tezuka, que só se limitou aos vocábulos pronunciados, sem ao menos informar o seu colega acerca da insuficiência disso - teria captado a epifania na carnadura dos signos pictográficos, isto $e$, que a cerejeira cereja, coisa que não se pode discernir, apenas auscultando o dizer da palavra. E teria percebido mais, posto que metafórico é o funcionamento do ideograma, a metáfora "florchameja", verdadeiro solo do pensamento feito poesia, ou da poesia do pensamento.

Em consonância com essa sua notação, o poema de que tratamos indica-nos a carga sensível, sígnica, de onde floresce, na obra de Haroldo de Campos, a poesia do pensamento que tem o seu contraforte na metáfora: do chão verbal dos significados ao subsolo dos componentes rítmico-semânticos, dos acordes de som e de sentido, ao relevo gráfico da palavra escrita. "Meisterludi ensinou-lhe o peso das vogais/Pluvia e diluvio/ sombra e umbra/penumbra" ("Ciropédia ou a Educação do Príncipe"). Ensinou o poeta a descer ao pré-categorial e ao pre-reflexivo, a esse ínfero, a esse limbo do pensamento, oscilante entre a língua e a palavra, entre o semiótico e o semântico, que um Giorgio Agambem chama de infância da linguagem.

Tendo rejeitado a dualidade do significado e do significante, como sombra metafísica do ente, Heidegger colocou sob suspeita, pela mesma razão, a metáfora. Segundo ele, uma réplica da "separação do sensível e do não-sensível como dois domínios auto-subsistentes" (Satz von Grund, pp. 88-9). Quando ele diz que "o metafórico só existe no interior da metafísica", está concedendo demais à metafísica - esquecido de tudo o que o pensamento dos pré-socráticos deve à metáfora - e concedendo pouco à metáfora, como se esquecesse que ele é o ato próprio da linguagem, a sua energeia, para dizê-lo com Humboldt, ou o princípio do seu jogo, para dizê-lo com Wittgenstein. Dá-se porém 
que essa mesma palavra, "jogo", uma das mais eminentes do pensamento heideggeriano da última fase, que lhe permitiu juntar semelhanças numa só expressão, Zeit-Spiel-Raum ("espaço de jogo do tempo"), da essencialização do ser, é, como grande metáfora, palavra de poeta, da mesma famnlia de outras tantas figuras constelares - clareira, velamento, iluminador, Quadripartite - que são, ao mesmo tempo, conceitos-limite da meditação do pensador, e tropos do seu personalíssimo estilo filosófico, a cuja órbita de confluência poética, pertencem as verbalizações de substantivos, a exemplo de Die Welt weltet ("o mundo mundeia"), Die Zeit zeitigt ("o tempo tempora"), das Ding dingt ("a coisa coiseia"). Heidegger - observa com justeza Henri Meschonnic - est une aventure poétique arrivé à la langue allemande. Ses commentaires de poèmes font des parapoèmes..." ("Chemins perdus chez Heidegger", in Le Signe et le Poème, p. 379). E parapoéticos são os comentários do filósofo à poesia, glosando o poema com o poema, porque ao excluir a constituição simbólica da linguagem, ele excluiu, ipso facto, a metalinguagem. Daŕ a aporia da prática meditante do filósofo, empenhado em fazer falar a linguagem (zum Wort kommt). Nesse limite hermenêutico ou se retorna ao conceito, e assim ao elemento reflexivo, o que Heidegger quer evitar juntamente com a metalinguagem, ou se concede iniciativa às palavras, numa passagem a Mallarmé da filosofia à poesia.

Agora podemos perceber que o nono verso de "Aisthesis, Kharis: Iki" é uma citação irônica da tautologia poética Das Ding ding, tentativa de topologia do ser. A coisa coiseia como a cerejeira cereja e a flor chameja. A ironia da citação nessa glosa heideggeriana, que como koan se apresenta, faz ver que o pensador de Ser e Tempo chegou pelo estilo auricular de sua última filosofia - mais hebraico do que grego, segundo observa Marlène Zarader (La Dette Impensée - Heidegger et l'Héritage Hébraique) - ao escrever Das Ding dingt, a um resultado análogo àquele a que já chegara um estilo de poesia medido pela visualidade cubista e pela inteligência chinesa:

\section{" (como pound olhou para ming ( ) sollua}

\section{com olho cubista de gaudier-brzeska}

$$
\text { depois de dar ouvido a fenollosa)" }
$$

Nesse passo, a glosa de Haroldo de Campos amplia-se sutilmente a um dos principais temas "De uma Conversação da Linguagem": o perigo de descaracterização da cultura do Extremo-Oriente, devido à expansão planetária da técnica, e que, segundo o professor Tezuka, atingiu Rashomon, o filme de Kurosawa, mais ocidental que oriental. Os dois professores esqueceram de considerar a contraparte desse processo iniciada no século XIX pela retrojeção da cultura intelectual e espiritual do Extremo-Oriente na européia, canalizada por Pound e Fenollosa para a poesia no tempo de sua modernidade.

Isso tudo levado em conta, se agora meditarmos no título do poema de Haroldo de Campo, "Aisthesis, Kharis: Iki", veremos que a ironia do comentário se prolonga na ironia da História: as duas matrizes gregas, a profana aisthesis e a kharis sacral, são postas em correspondência com $i k i$ que as sintetiza. Levando-nos para fora do âmbito do poema, esta correspondência assinala o alcance histórico dessas matrizes. Última notação do exemplarismo dos versos que examinamos, o seu título é um emblema da proximidade entre poesia e pensamento, ou, se quisermos, entre poesia e filosofia. "Poetar e pensar necessitam-se mutuamente.." ("Dichten und denken brauchen einander..."). Podemos acrescentar que se necessitam mutuamente ainda mais depois que a filosofia chegou ao seu acabamento, ao auge de suas possibilidades enquanto metafísica, e que a poesia universal, no sentido da mistura de gêneros e formas de expressão, do prosaico e do poético, a que se referiu o romântico Friedrich Schlegel, passou a conjugar estilos e heranças poéticas do passado.

Mas em Haroldo de Campos, a proximidade entre poesia e pensamento, conforme atesta a sua glosa heideggeriana, faz-se à custa da reflexão introduzida no jogo da linguagem, o que Heidegger não admitiria. De onde se conclui que na obra de meu interlocutor, em constante dialogação com pensadores-poetas como Heráclito e AlGhazali, e com poetas-pensadores como Dante, Goethe e Leopardi, a poesia do pensamento, tanto na criação quanto na tradução recriadora, complementa-se pelo pensamento da poesia, histórica e criticamente considerado. 